\title{
Date of Cardiac Therapeutic Procedure
}

National Cancer Institute

\section{Source}

National Cancer Institute. Date of Cardiac Therapeutic Procedure. NCI Thesaurus. Code C80455.

The date that a specific cardiac therapeutic procedure was performed. 